\title{
UMA ABORDAGEM DE LAYOUT PARA A GESTÃO DE ESTOQUE EM UMA MINERADORA
}

\author{
Murilo Almeida Costa - murilo_almeida30@ hotmail.com $^{1}$ \\ Vitor Martins Vale Menezes -vitorvmenezes@ outlook.com \\ Gilberto Sousa Lopes - Gilberto.sousa@ professor.unis.edu.br ${ }^{2}$ \\ Mario César Fialho de Oliveira - mc-mariocesar@hotmail.com \\ Zarur de Oliveira Silvano - zarurs@yahoo.com.br
}

\section{RESUMO}

O presente trabalho tem por objetivo mostrar a importância do estudo de tempo e movimento visando à otimização do processo de coleta do minério no pátio e a eficiência da simulação computacional utilizando o software Arena, a fim de propor uma alteração do layout existente. Para isto, foi desempenhado um estudo de caso na área de expedição de uma mineradora. A metodologia utilizada baseia-se em um estudo sobre layout e simulação computacional. Com a utilização desta, foi proposto uma alteração no layout estudado baseado em dados obtidos através do software. Os resultados mostraram que o novo layout proposto é mais viável, devido principalmente a redução do tempo de deslocamento realizado pelo caminhão, visto que o layout proposto troca a posição de uma pilha com maior demanda em um local desprivilegiado por uma pilha de menor demanda em uma posição que apresenta um menor tempo para o processo de coleta.

Palavra - chave(s): Estoque. Layout. Software Arena

\begin{abstract}
The present work aims to show the importance of the study of time and movement aiming at the optimization of the ore collection process in the yard and the efficiency of the computer simulation using the Arena software, in order to propose a change to the existing layout. For this, a case study was carried out in the shipping area of a mining company. The methodology used is based on a study on layout and computational

\footnotetext{
${ }^{1}$ Graduandos em Engenharia de Produção das Faculdades Integradas de Cataguases - Grupo Unis

${ }^{2}$ Professores especialistas nas Faculdades Integradas de Cataguases - Grupo Unis
} 
simulation. Using this, a change in the studied layout was proposed based on data obtained through the software. The results showed that the proposed new layout is more feasible, mainly due to the reduction of the travel time made by the truck, since the proposed layout changes the position of a pile with the highest demand in a disadvantaged location for a pile with the lowest demand in a position that presents a shorter time for the collection process.

Keywords: Stock. Layout. Software Arena.

\section{INTRODUÇÃO}

Este trabalho se contextualiza em demonstrar a importância e vantagens da aplicação de layout para redução do tempo de coleta e melhor eficiência na linha de transporte de uma organização, visando uma gestão estratégica eficaz. Atualmente, podese observar a grande concorrência e busca incessante por competitividade no contexto atual de mercado, evidenciando que existem ganhos substanciais ao administrar todo gasto e tempo indevido nas atividades, de modo a coordenar e organizar todos os processos de forma eficiente e centralizada, satisfazendo todas as partes interessadas da empresa direcionadas pelo planejamento estratégico, uma vez que ele norteia todas as ações e metas baseando na visão e aspirações gerenciais. Com a utilização da ferramenta de simulação do processo, este estudo busca identificar o melhor posicionamento das pilhas, facilitando com a identificação dos dados do cenário proposto. Através do método de revisão bibliográfica, este trabalho abordará a aplicação, conceito e os resultados com a análise de dados e do software Arena.

O presente trabalho se justifica em contribuir para a gestão da organização e para todos os profissionais ligados ao processo logístico da empresa, pois eles trabalham a fim de serem fortes motores para uma boa gestão de estoque, tendo em vista todo o planejamento da organização e seus objetivos. Ele é categorizado no pátio de estoque de minério acabado, para propor, através de estudos, um layout ideal com base em simulação computacional, pois são sistemas capazes de simular processos obtendo informações importantes para várias áreas da organização para a tomada de decisão.

A contribuição para o presente trabalho tem como objetivo propor, com base em estudos, um layout fundamentado em simulações do processo de alimentação dos 
caminhões no estoque de uma empresa, a partir de embasamento teórico e visitas realizadas iremos contribuir com a implantação software Arena para simulações e análise de dados que nos guiou com informações de quais pilhas demandam mais prioridade, embasado em dados históricos do tempo de coleta na balança de entrada e de saída da empresa.

Analisar a partir dos dados gerados pelo software Arena o ganho com o novo layout na empresa objeto de estudo, além de analisar o tempo ganho no processo. Com os dados obtidos em duas simulações, a exposição dos dois cenários apresentados no trabalho, estará revelando a produtividade em percentual dos dois cenários.

\section{METODOLOGIA}

O estudo foi realizado nos primeiros seis meses do ano de 2020 em uma mineradora situada no estado de Minas Gerais. Para melhor entendimento do assunto abordado, dotou-se também de uma pesquisa bibliográfica. A pesquisa bibliográfica foi realizada a partir do levantamento de referências teóricas já analisadas e publicadas por meios de livros, artigos científicos, páginas de web sites. O estudo foi realizado no Pátio de minério beneficiado da empresa, onde é considerado o estoque armazenado de produto acabado. Para obtenção dos dados de movimentação de entrada e saída de minério beneficiado no pátio foi realizada uma visita na empresa, caracterizando a pesquisa como um estudo de caso.

Em entrevista com o gestor responsável pelo pátio, que ocupa a posição de supervisor de PCP em um período de quatro anos, questionamos ao entrevistado a respeito de como foi distribuído as pilhas na expedição e foi possível verificar que a organização não detinha de pleno conhecimento do tempo e movimento na operação de carregamento traz, tornando válido o estudo de caso. Este método a ser utilizado trata-se de uma das técnicas de simulação de tempo e movimento, o software Arena se conceitua em simular um modelo de layout com a apresentação dos resultados em relatório gerencial.

Além disso foi possível observar que pode-se aplicar o software Arena para simulação do cenário antigo em relação ao cenário atual proposto. Este software se consiste em uma ferramenta para análise de cenários e realiza simulações de processos. Com sua devida aplicação nos dois cenários, a ferramenta Arena se compromete em 
apresentar a diferença de tempo gasto no layout antigo e no novo. A ferramenta possibilita o desenho dos dois processos, construindo em forma de fluxograma e alimentando com as informações de tempo das demandas, o software se responsabiliza em simular em um período de 80 horas de processo, que é o tempo máximo permitido pela versão de estudante do Arena, e apresentar os resultados no processo.

A aplicação foi a medida adotada para melhor acesso das maquinas e carretas no Pátio, visando posicionar as pilhas de minérios com layout estratégico. Para a construção do Layout, que representa a disposição das instalações, equipamentos e serviços, com o objetivo de máxima eficiência no processo, foi utilizado o software AutoCad 2020.

\section{REFERENCIAL TEÓRICO}

\subsection{IMPORTÂNCIA DA LOGÍSTICA}

Segundo Ballou (2004) É comum as empresas se preocuparem com meios para caracterizar seus produtos de seus concorrentes. Porém, vem acrescentando cada vez mais o reconhecimento da logística na tarefa de sair na frente. Isso acontece porque as empresas estão aprendendo que a logística afeta uma parte significativa dos custos da empresa e que ela pode ser usada para alcançar níveis mais elevados na participação do mercado e aumento do lucro.

"As empresas buscam através da logística uma inovação na qualidade de serviços, satisfação do cliente e consequentemente, vantagens competitivas e maior flexibilidade na gestão empresarial” (RODRIGUES et al. 2015). A contribuição da logística é notável em todos os cenários das organizações, um bom layout para o estoque contribui de forma efetiva no resultado da logística de entrega do produto, reduzindo o fluxo e gargalos no Pátio de estoque da empresa.

\subsection{GESTÃO DE ESTOQUE}

De acordo com Bowersox et al. (2008) a gestão vem sendo estudada e discutida por acadêmicos e gestores desde a década de 50, gerando uma considerável quantidade 
de pesquisa desenvolvida, a fim de propor métodos para calcular parâmetros e estoques de maneira a atingir o ótimo ponto.

A administração de estoque é fundamental para a empresa, pois é um processo complexo, que procura conciliar, níveis de estoques suficientes para evitar interrupções prolongadas nas operações da empresa, e minimizar o capital investido nos itens estocados, de forma a reduzir o custo do estoque na composição global de custos da empresa. (CAMPOS 2009).

Segundo Campos (2009) a administração de estoque está ligada ao conceito geral de uma boa cadeia de suprimentos, deve ser administrado de forma integrada desde a compra de materiais ou matérias primas até a entrega do produto ao consumidor final que são considerados o ponto de destino de uma cadeia de suprimentos.

O posicionamento das instalações ao longo de uma cadeia de suprimentos é de extrema importância na tomada de decisão, pois está interligado à estruturação do sistema logístico. As instalações podem influenciar um maior investimento em ativos fixos, de difícil reversão a curto e médio prazo, o que implica em altos custos para reposicionar a instalação em um novo local, o que demonstra a real importância deste processo. (MACEDO e FERREIRA, 2011).

\subsection{LAYOUT DE ESTOQUE}

Para Ballou (2006) o LAYOUT de estoque é a disposição de homens, máquinas e materiais para proporcionar a integração entre o fluxo de materiais e manuseio de equipamentos necessários de movimentação para que a estocagem ocorra de maneira a gerar economia.

"O melhor LAYOUT de posicionamento de itens estocados depende do número de pontos de expedição, quando o armazém possui apenas um local para expedição, os produtos ou classes de itens com maior rotatividade devem ser posicionados próximos a ele" (BATTESINI, 2016).

Para Hassan (2002), um dos aspectos mais importantes para a concepção e eficiência de um armazém é seu LAYOUT, visto que o arranjo físico, além de auxiliar significativamente na resolução de diversos problemas, aloca os itens no estoque de forma satisfatória, fazendo com que o armazém seja capaz de suportar seu funcionamento, sendo assim a proposição do LAYOUT deve, ainda, levar em consideração o arranjo das áreas funcionais do armazém e determinar questões fundamentais como: quantidade e 
localização das docas, pontos de entrada e saída de material, número de corredores, as suas dimensões e orientação, estimando necessidades de espaço, projetando o padrão de fluxo e formando as áreas de picking, também desempenha um papel fundamental nos negócios da empresa, na qual o arranjo físico mais adequado depende das suas condições operacionais e de suas características tais como: Acessibilidade, flexibilidade, adaptabilidade, distribuição dos movimentos.

\section{RESULTADOS E DISCUSSÕES}

A alimentação dos caminhões que coletam minério no pátio, é realizada pela entrada e saída já predominada como padrão no processo de coleta.

Os dados obtidos para a simulação, foram disponibilizados pela empresa objeto de estudo, onde esses dados representam a contagem desde o momento da entrada do caminhão no pátio, passando pela balança primária, e encerrando na sua passagem pela balança secundária que tem ligação direta à rodovia.

Abaixo segue visualização da operação realizada no cenário atual, onde é ilustrado no Autocad a operação de coleta no pátio de minério beneficiado. A expedição é composta por oito pilhas, sendo representadas de $1 \mathrm{~A}$ à $8 \mathrm{~A}$. Segue a Figura 1 para visualização:

A figura representada abaixa, apresenta o layout atual, onde será analisado os dados obtidos de tempo de cada pilha. A representação mostra o caminhão que transita entre as pilhas e se estaciona ao lado da pilha que será realizada a coleta.

Figura 1:Layout atual do pátio de minério beneficiado (Expedição)

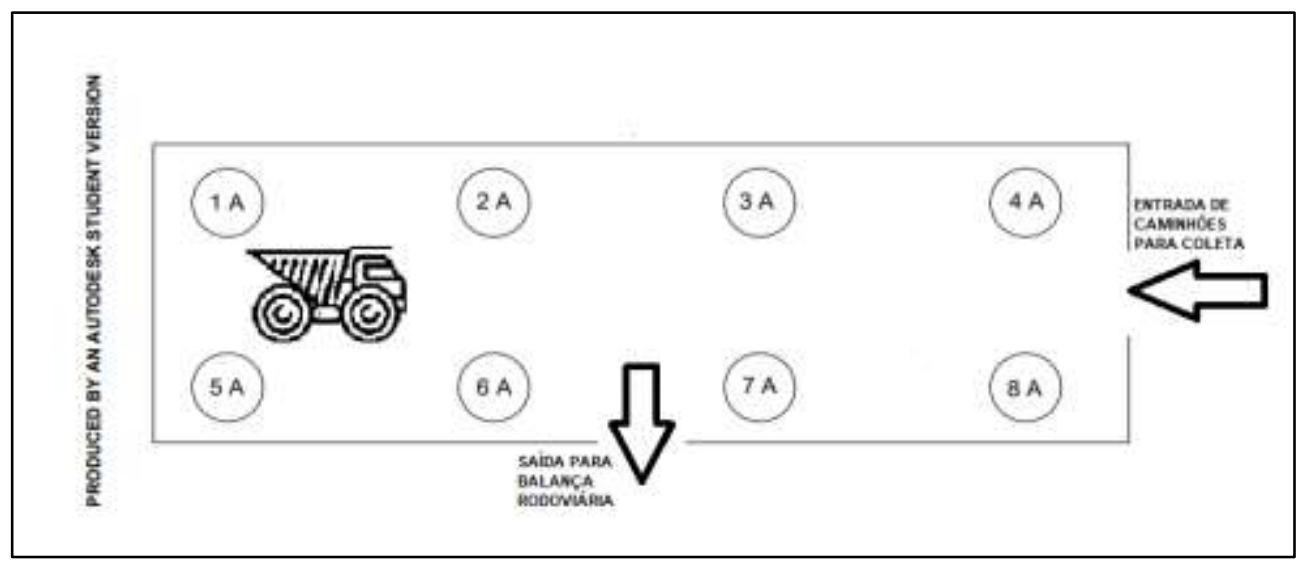

Fonte: Os autores. Ano 2020. 
Na figura abaixo, é apresentado os dados de tempo do processo em relação a demanda destinada em cada pilha do estoque.

Figura 2: Relação de tempo de coleta x Demanda por minuto

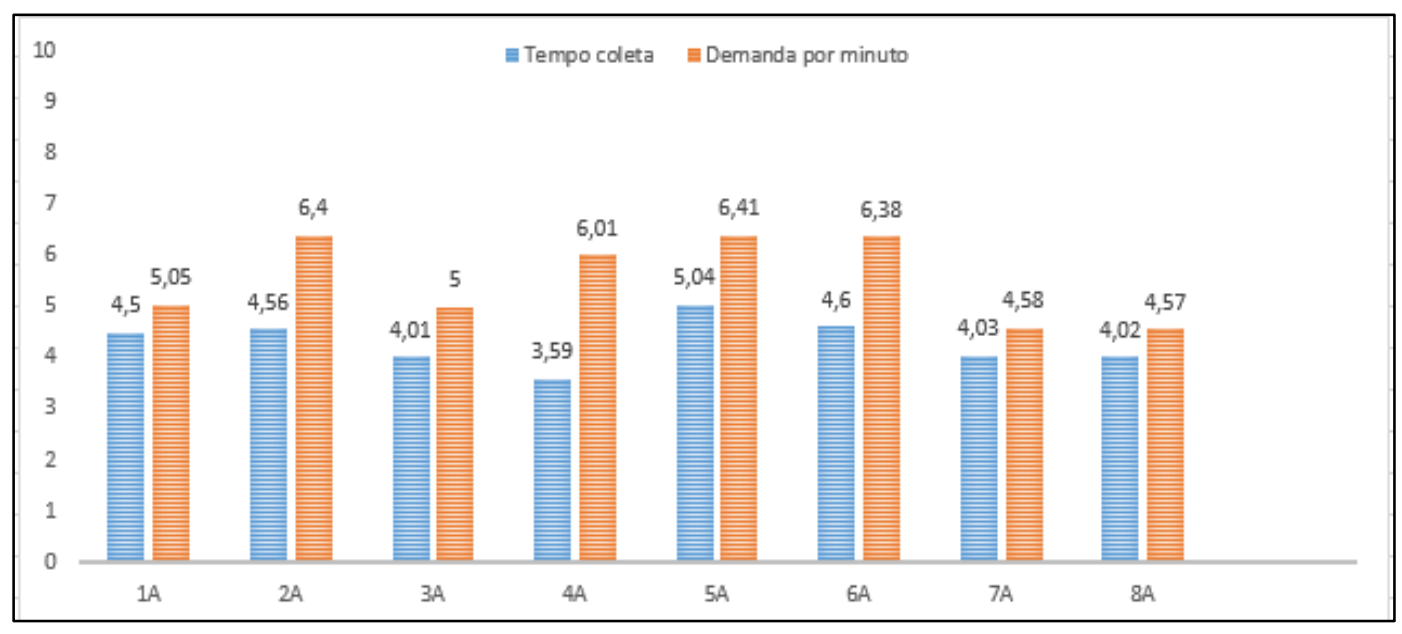

Fonte: Os autores. Ano 2020.

A análise tem como objetivo demonstrar a diferença que foi encontrada em percentual maior na pilha 1A, onde o tempo médio de execução representa $89,11 \%$ do tempo médio de demanda por minuto. A pilha 4A também traz uma informação importante, visto que ela representa um menor percentual, o tempo médio de execução representa apenas 59,73\% do tempo médio de demanda por minuto, estes resultados são apresentados na Tabela 1. Segue abaixo uma relação do percentual referente a cada pilha:

Tabela 1 :Percentual do tempo de coleta x Tempo da demanda média

\begin{tabular}{cccc}
\hline Pilha & Coleta & Demanda por Minuto & Percentual do tempo de Coleta \\
\hline 1A & 4,5 & 5,05 & $89,11 \%$ \\
2A & 4,56 & 6,4 & $71,25 \%$ \\
3A & 4,01 & 5 & $80,20 \%$ \\
4A & 3,59 & 6,01 & $59,73 \%$ \\
5A & 5,04 & 6,41 & $78,63 \%$ \\
6A & 4,6 & 6,38 & $72,10 \%$ \\
7A & 4,03 & 4,58 & $87,99 \%$ \\
8A & 4,02 & 4,57 & $87,96 \%$ \\
\hline
\end{tabular}

Fonte: Os autores. Ano 2020. 
$\mathrm{Na}$ análise acima, foi levantado como destaque a pilha 1A com o percentual maior e a 4A representando o percentual menor, onde a simulação no software Arena vai demonstrar a eficiência na movimentação de troca da pilha 1A pela pilha 4A.

A tabela acima apresenta os dados de tempo do processo em relação a demanda destinada em cada pilha do estoque. O cálculo para obter o percentual referente a cada pilha foi um cálculo básico de regra de três, onde foi feito a divisão do tempo de coleta pelo tempo da demanda por minuto e convertido esse valor em percentual, multiplicando por 100. Desmistificando os dados, a tabela acima tem como objetivo demonstrar que o tempo médio de entrada de demanda representa cerca de $89,11 \%$ do tempo médio para executá-la. A pilha 4A é o oposto, pois ela recebe uma demanda média de um caminhão a cada 06:01 minutos, e um tempo de execução de 03:59 minutos, que representa apenas $59,73 \%$ do tempo da demanda por minuto na pilha, ou seja, a pilha possui uma demanda pequena e está em uma posição privilegiada. Segue representado na figura abaixo a simulação no software Arena do cenário atual:

Figura 3: Número de caminhões que carregaram na pilha 1A

\begin{tabular}{|c|c|c|}
\hline $20: 19: 19$ & Category Overview & outubro 6,2020 \\
\hline \multicolumn{3}{|c|}{ Unnamed Project } \\
\hline Replications 1 & Time Units: Seconds & \\
\hline \multicolumn{3}{|c|}{ Key Performance Indicators } \\
\hline $\begin{array}{l}\text { System } \\
\text { Number Out }\end{array}$ & $\begin{array}{c}\text { Average } \\
969\end{array}$ & \\
\hline
\end{tabular}

Fonte: Os autores. Ano 2020.

Na Figura 3 é constatado o número de caminhões que carregaram na pilha $1 \mathrm{~A} \mathrm{em}$ um período de 80 horas de trabalhos (Number Out), totalizando novecentos e sessenta e nove caminhões. Esse número é relativo ao processo antigo, levando em consideração todo tempo de deslocamento referente ao processo de movimentação do caminhão no pátio e o enchimento com a carregadeira. A ilustração abaixo também se refere aos dados obtidos com a simulação. 
Figura 4:Tempo de espera em duas semanas de operação

\begin{tabular}{|lrrrr||}
\hline \hline Queue & & & & \\
\hline Time & & & & \\
& & & & \\
Waiting Time & Average & Half Width & $\begin{array}{r}\text { Minimum } \\
\text { Value }\end{array}$ & $\begin{array}{c}\text { Maximum } \\
\text { Value }\end{array}$ \\
\hline 1A.Queue & 15559.22 & (Correlated) & 0.00 & 33016.41 \\
\hline
\end{tabular}

Fonte: Os autores. Ano 2020.

A Figura acima é o tempo mínimo, médio e máximo da primeira simulação. Abaixo segue os dados na Tabela 2 representando a simulação em tabela.

Tabela 2: Comparação de tempo e processos executados.

\begin{tabular}{lccc}
\hline \multicolumn{4}{c}{ Relação do tempo de espera do processo atual } \\
\hline \multicolumn{2}{c}{ Tempo de rendimento (Segundo) } & Horas & $\mathrm{N}^{\circ}$ de coletas realizadas \\
Tempo Mínimo & 0 & 0 & 969 \\
Tempo Médio & 15559,22 & $04: 32$ & 969 \\
Tempo Máximo & 33016,41 & $09: 17$ & 969 \\
\hline
\end{tabular}

Fonte: Os autores. Ano 2020.

Essa tabela consiste no tempo de realização, demonstrando o rendimento atual de movimentação. A próxima simulação já é a representação dos resultados no layout proposto.

Figura 5: Numero de caminhões que carregaram na pilha 1A após mudança de layout.

\begin{tabular}{|lcc|}
\hline 20:33:16 & Category Overview & outubro 6, 2020 \\
\hline Unnamed Project & & \\
\hline Replications 1 & Time Units: & Seconds \\
& Key Performance Indicators \\
System & Average \\
Number Out & 1,055 \\
& \\
\hline
\end{tabular}

Fonte: Os autores. Ano 2020.

Utilizando as projeções propostas de melhorias na mudança de layout e redução dos tempos de deslocamento, é possível realizar uma melhoria do processo de carga no 
pátio. A mudança de uma pilha que tem muita demanda para uma posição mais estratégica dentro da expedição seria uma ideia para melhorar o tempo de atuação e deslocamento dos caminhões dentro do pátio, resultando em um tempo de espera inferior (Figura 6), e um aumento de caminhões carregados conforme informado na imagem acima (Figura 5). Totalizando o número de mil e cinquenta e cinco caminhões.

Figura 6:Tempo de espera em duas semanas de operação

\begin{tabular}{|lcccc|}
\hline Queue & & & & \\
\hline & & & & \\
Time & & & & \\
Waiting Time & & & Minimum & Maximum \\
& Average & Value & \\
\hline 1A.Queue & 789.69 & (Correlated) & 0.00 & 4047.88 \\
\hline
\end{tabular}

Fonte: Os autores. Ano 2020

A Figura 6 tem como objetivo trazer três dados importantes, o tempo de espera mínimo, médio e máximo. O tempo mínimo é representado como zero, pois as primeiras viagens nas operações não geram filas, nas próximas viagens começa um fluxo maior no pátio devido a pequena tolerância que existe entre o tempo de coleta $\mathrm{x}$ tempo médio de caminhões por minuto. Neste segundo cenário de simulação é representado a redução significativa no tempo de espera. Segue abaixo os dados apresentados na nova simulação.

Tabela 3: Comparação de tempo e processos executados

\begin{tabular}{lccc}
\hline \multicolumn{4}{c}{ Relação do tempo de espera do processo proposto } \\
\hline \multicolumn{2}{c}{ Tempo de rendimento (Segundo) } & Horas & $\mathrm{N}^{\circ}$ de coletas realizadas \\
Tempo Mínimo & 0 & 0 & 1055 \\
Tempo Médio & 789,69 & $00: 13$ & 1055 \\
Tempo Máximo & 4047,88 & $01: 07$ & 1055 \\
\hline
\end{tabular}

Fonte: Os autores. Ano 2020.

A partir do levantamento de dados com base nas novas projeções, observa-se uma melhoria no tempo de rendimento mínimo, médio e máximo, onde apenas o médio é levado em consideração e obteve-se um aumento no número de peças produzidas e redução do tempo de esperar para se iniciar um novo processo. Importante ressaltar que 
estes dados são baseados em apenas duas semanas de trabalho (80 horas). Segue abaixo os dados representando uma melhor eficiência na produtividade no processo de coleta no pátio.

Tabela 4: Percentual do tempo de coleta $\mathrm{x}$ Tempo da demanda média

\begin{tabular}{cccc}
\hline Pilha & Coleta & Demanda por Minuto & Percentual do tempo de Coleta \\
\hline 4A & 3,59 & 5,05 & $71,09 \%$ \\
2A & 4,56 & 6,4 & $71,25 \%$ \\
3A & 4,01 & 5 & $80,20 \%$ \\
1A & 4,5 & 6,01 & $74,88 \%$ \\
5A & 5,04 & 6,41 & $78,63 \%$ \\
6A & 4,6 & 6,38 & $72,10 \%$ \\
7A & 4,03 & 4,58 & $87,99 \%$ \\
8A & 4,02 & 4,57 & $87,96 \%$ \\
\hline
\end{tabular}

Fonte: Os autores. Ano 2020.

Na tabela acima é apresentado o percentual do quanto o tempo de coleta representa no tempo de demanda. A pilha 4A na primeira análise, que representa o cenário atual, tem um percentual de 59,73\% de tempo de coleta, já no cenário proposto ela sobe para 71,09\%. A princípio esse aumento nos traz um desconforto com os dados, porém se analisarmos o processo como um todo, a pilha 1A tinha um percentual de $89,11 \%$ de tempo de coleta e agora na sua nova posição tem um percentual de $74,88 \%$. Segue abaixo figura 7 para a ilustração do cenário proposto de layout.

A ilustração do layout representada abaixo, evidencia em destaque na cor amarela as pilhas 1A e 4A, que tiveram uma movimentação, seguindo a orientação dos resultados apresentados acima.

Figura 7: Layout proposto do pátio de minério beneficiado (Expedição)

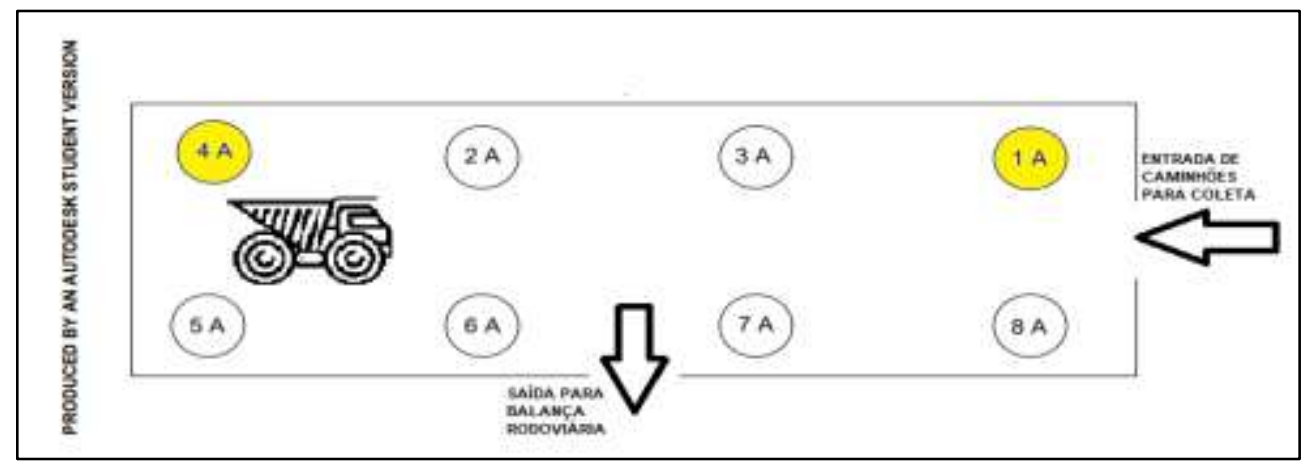

Fonte: Os autores. Ano 2020. 
A representação acima da Figura acima, destaca a movimentação que teve da pilha 1A com a pilha $4 \mathrm{~A}$.

\section{CONSIDERAÇÕES FINAIS}

A contribuição para o presente trabalho tem como objetivo propor, com base em estudos, um layout fundamentado em simulações do processo de alimentação dos caminhões no estoque de uma empresa, e com a implantação software Arena para simulações e análise de dados que nos guiou com informações de quais pilhas demandam mais prioridade, embasado em dados históricos do tempo de coleta na balança de entrada e de saída da empresa.

Com base em análises através de cronometragem virtual com utilização do software Arena, obtiveram-se resultados que indicam "perda" de tempo no processo de movimentação indevida no pátio. Tal perda se apresenta devido layout atual, ao tempo de espera da movimentação e de deslocamento do caminhões em transitar pelo pátio.

Analisando o tempo de coleta como um todo, apenas as d pilhas 1A e 4A sofreram aumento e diminuição do percentual do tempo x demanda. Consolidando os dados temos que no cenário antigo a soma dos dois: percentual da pilha $1 \mathrm{~A}(89,11 \%)+$ percentual da pilha $4 \mathrm{~A}(59,73 \%)$ soma um total superior a soma do percentual da pilha $1 \mathrm{~A}(74,88 \%)+$ percentual da pilha 4A $(71,09 \%)$.

Desta forma, analisando o tempo e movimento do trajeto em questão, constatouse uma mudança do layout da pilha 1A localizada no fim da expedição por uma localizada no início, a 4A. Assim, o tempo de deslocamento realizado pelo caminhão foi reduzido, visto que o layout proposto troca a posição de uma pilha com maior demanda em um local desprivilegiado por uma pilha de menor demanda em uma posição que apresenta um menor tempo para o processo de coleta.

Para futuros trabalhos recomenda-se a introdução de ferramentas de análise e planejamento estratégico de suas operações de movimentação no estoque, pois as operações e movimentações não seguem uma metodologia e não obtém nenhum tipo de ferramenta que analisa esses dados, o estoque e as movimentações são realizadas conforme rotina costumeira dos antepassados que atuaram na empresa. 


\section{REFERÊNCIAS BIBLIOGRÁFICAS}

BALLOU, R. H. The evolution and future of logistics and supply chain management. Produção, v.16, n.3, p.375-386, set./dez. 2006. Disponível em: http://www.scielo.br/scielo.php?pid=S0103-65132006000300002\&script= sci_arttext. Acesso em: 27 Maio. 2020.

BATTESINI - Otimização do Layout de Produção de um processo de pintura de Ônibus. Disponível em: http://repositorio.gv.ifmg.edu.br:8080/bitstream/123456789/111/1/tcc_proposta_layout_ estoque.pdf $>2016$. Acesso em 27 de Maio de 2020

BOWERSOX, D. J.; CLOSS, D. J. Logística empresarial: o processo de integração da Cadeia de Suprimento. 1. ed. Atlas, 2001, 594 p.

CAMPOS 2009 - Arranjo do Layout de Estoque para equipamentos de proteção individual. Disponivel em < https://www.lume.ufrgs.br/handle/10183/18949> 2009. Acesso em Acesso em 30 de Maio de 2020

HASSAN, M. M. D. A framework for the design of warehouse layout. Facilities, v.20, n. 13/14, p. 432-440, 2002. Disponível em: https://www.emerald.com/journals.htm . Acesso em: 02 Junho. 2020.

MACEDO, N. L. F.; FERREIRA, K. A. Diagnóstico da gestão de armazenagem em uma empresa do setor de distribuição. In: Encontro nacional de engenharia de produção, 31, 2011, Belo Horizonte. Anais...Belo Horizonte, 2011. Disponível em: <http://www.abepro.org.br/biblioteca/enegep2011_TN_STP_135_857_17640.pdf>.

Acesso: 22 Maio. 2020.

RODRIGUES, S. et al. Logística: o endereçamento como ferramenta fundamental na armazenagem e estocagem. Faculdade de Tecnologia de Santa Catarina: Santa Catarin a: 2015. Disponível em Acesso em 01 Junho. 2020 